\title{
Effect of autogenous tooth bone graft with membrane on Class II furcation defects in dogs: A histologic and histomorphometric study
}

\author{
Keon-Il Yang ${ }^{1,3}$, Ah-Young Cho ${ }^{1}$, Jin-Young Yang ${ }^{1}$, Hong-In Shin ${ }^{2}$, Won-Pyo Lee ${ }^{1,3}$, Byung-Ock Kim ${ }^{1,3}$, and \\ Sang-Joun $\mathrm{Yu}^{1,3 *}$
}

${ }^{1}$ Department of Periodontology, School of Dentistry, Chosun University, Gwangju 61452, Republic of Korea

${ }^{2}$ Department of Oral pathology, School of Dentistry, Kyungbook University, Daegu 41940, Republic of Korea

${ }^{3}$ Oral Biology Research Institute, Chosun University, Gwangju 61452, Republic of Korea

(Received Dec 12, 2017; Revised version received Feb 12, 2018; Accepted Feb 12, 2018)

\begin{abstract}
The study evaluated the efficacy of combining autogenous tooth bone grafts with membranes in surgically created class II furcation defects. Thirty teeth of 10 dogs were assessed. Furcation defects $\left(5 \times 4 \times 3 \mathrm{~mm}^{3}\right)$ were created in the lower third and fourth premolars. Defects in the control, experimental-1, and experimental-2 groups were treated with non-resorbable membranes only, autogenous tooth bone grafts with non-resorbable membranes, and autogenous tooth bone grafts with resorbable membranes, respectively. Healing patterns were observed 4 to 8 weeks after treatment. Mesio-distal sections were obtained and stained with hematoxylin and eosin, and histological and histomorphometrical analyses were performed. Four weeks after treatment, connective tissue and autogenous tooth bone graft materials with newly formed bone were observed. Partial recovery of periodontal ligament-like tissue and formation of cementum-like tissue at root surfaces also occurred. Eight weeks after treatment, mature bone tissue formation was noted. In addition, regular thickness of cementum-like tissue at root surfaces, and improved periodontal ligament-like tissue were observed. Areas of newly formed tissue were $92.2 \% \pm 13.0 \%, 97.4 \% \pm 4.4 \%$, and $98.1 \% \pm 2.8 \%$ at 4 weeks after treatment, and $96.7 \% \pm 3.7 \%, 96.8 \% \pm 5.7 \%$, and $99.6 \% \pm 0.8 \%$ by 8 weeks post-treatment, in the control, experimental-1, and experimental-2 groups, respectively. Regeneration of defective tissues occurred in the experimental group compared with the control group, but not significantly. This study showed that combining autogenous tooth bone grafts with membranes in class II furcation defects improves healing efficiency.
\end{abstract}

KEY WORDS: Bone substitutes, Furcation defects, Guided tissue regeneration

\section{Introduction}

Periodontal treatments aim to prevent the progression of periodontal diseases and, where possible, regenerate periodontal tissues damaged by periodontal diseases. Various types of cells function in periodontal tissue defects during regeneration after periodontal treatment, including junctional epithelium-derived cells, gingival connective tissuederived fibroblasts, periodontal ligament-derived fibro-

\footnotetext{
*Corresponding author: Sang-Joun Yu

Department of Periodontology, School of Dentistry, Chosun university, 309 Pilmun-daero, Dong-gu, Gwangju 61452, Republic of Korea Tel.: +82-62-220-3850, Fax: +82-62-224-4664

E-mail: sjyu78@chosun.ac.kr
}

blasts, mesenchymal cells, and osteoblasts [1]. However, since cells derived from junctional epithelia or connective tissues rapidly migrate and differentiate, leading to healing with junctional epithelia and root surface resorption, they interfere with regeneration of lower periodontal tissues.

The guided tissue regeneration technique is a surgical method that blocks such cells, derived from junctional epithelia or connective tissues, from using a barrier membrane, and induces the regeneration of new periodontal tissues from cells derived from lower periodontal ligaments and alveolar bone. This surgical method leads to desirable outcomes in intrabony defects [2-4]. Pontoriero et al. [5,6] reported that the guided tissue regeneration technique led to new attachments and alveolar bone formation in Class II furcation defects; however, success 
rates were lower when Class III furcation defects were $\geq$ $4 \mathrm{~mm}$.

Barrier membranes are classified as non-resorbable and resorbable, depending on their bio-resorbable properties. Non-resorbable membranes require secondary surgery for removal, with disadvantages including induction of alveolar ridge resorption [7], reduction of new tissue coverage [8], and high risk of membrane exposure and bacterial infection. Thus, resorbable membranes were developed, and these two types of membrane are currently used in clinical practice.

Machtei and Schallhorn [9] reported that regeneration outcomes improved when membranes and bone graft materials were used in combination for Class II furcation defects. Various bone graft materials have been applied for the regeneration of Class II furcation defects [10], with three functions: scaffolding during bone regeneration (osteoconductivity), promotion of differentiation into osteogenic cells (osteoinductivity), and direct contribution to bone regeneration (as bone graft materials contain osteogenic cells) [11].

Autogenous bone was thought to provide the best bone graft material for regeneration, as it serves all three aforementioned functions (bone regeneration, osteoconductivity, and osteoinductivity) [12]. However, autogenous bone has disadvantages, including limitations to the amount of collectible autogenous bone, unavoidable bone resorption, and the greater surgical area required to collect autogenous bone. To overcome these limitations, allogenic bone, heterogenic bone, and synthetic bone have been utilized in clinical practice, and efforts have ensued to develop more ideal bone graft materials [13].

The autogenous tooth bone graft material used in the present study is a new type of allogenic material, made of powder processed from extracted teeth, containing bone morphogenetic proteins. Decalcified dentin is reported to have osteoinduction capabilities [14,15], and Kim et al. reported that autogenous tooth bone graft material is biocompatible [16-23]. Commercialized and clinically applied since 2008 , it is mainly composed of hydroxyapatite, has a surface-type similar to autogenous bone, and a low crystal structure. It contains both minerals and organic components, and is reported to support bone healing by osteoinduction and osteoconduction [22,23].

To date, there are only a few studies that have explored the potential of autogenous tooth bone graft material for periodontal tissue regeneration; thus, the aim of this study was to evaluate the potential of autogenous tooth bone graft material for supporting the histological and histomorphometrical regeneration of periodontal tissue, for which both non-resorbable (i.e. Polytetrafluoroethylene; PTFE), and resorbable membranes were used for surgically created Class II furcation defects.

\section{Material and Methods}

\section{Experimental animals and materials}

This study was approved by the "Chosun University Institutional Animal Care and Use Committee" (CDMDIRB-1114-A85). Experimental animals were ten 6-monthold dogs that weighed $15-20 \mathrm{~kg}$. All were reared in the same condition, and had desirable systemic and oral conditions.

To manufacture the autogenous tooth bone graft material (Auto-BT ${ }^{\circledR}$, Korea Tissue Bank, Seoul, Korea), left and right mandibular first and second premolars and four incisors were used. Class II furcation defects were created on left and right mandibular third and fourth premolars, and the control and experimental groups were randomly selected.

The control group received only non-resorbable PTFE membranes (Cytoplast membrane ${ }^{\circledR}$, Osteogenics Biomedical, Inc, Lubbock, USA). For the experimental groups, defects were first filled with autogenous tooth bone graft material, and then covered with membranes. Depending on the type of membrane, the experimental groups were then divided into experimental group-1 that received nonresorbable PTFE membranes, and experimental group-2 that received resorbable collagenous membranes (Osse$\left.\operatorname{oguard}^{\circledR}, 3 \mathrm{i}, \mathrm{NJ}, \mathrm{USA}\right)$.

\section{Manufacture of autogenous tooth bone graft mate- rial (ATBG)}

After removal of soft tissue and dental pulp around the extracted teeth, teeth were washed with distilled water for at least $30 \mathrm{~min}$, then rapidly frozen with liquid nitrogen at $\leq-160^{\circ} \mathrm{C}$ for at least $30 \mathrm{~min}$, ground to a $200 \mu \mathrm{m}-1000 \mu \mathrm{m}$ particle-sized powder, and finally washed with distilled water for at least $30 \mathrm{~min}$ to remove contaminants and residual soft tissue. Thereafter, the powder was washed three times in each of the following steps: 1) ultrasonic cleaning with pure or sterilized distilled water for 5 to $10 \mathrm{~min}, 2$ ) ultrasonic cleaning with hydrogen peroxide solution for 10 to 
$30 \mathrm{~min}$, and 3) ultrasonic cleaning with pure or sterilized distilled water for 5 to $10 \mathrm{~min}$. In this way, contaminants and residual soft tissues were eliminated. Thereafter, the powder was skimmed with a chloroform methanol solution for 3 to $12 \mathrm{~h}$, washed with distilled water for at least $1 \mathrm{~h}$, and dehydrated for $30 \mathrm{~min}$ to $2 \mathrm{~h}$ using a neutral ethyl alcohol. Finally, the powder was lyophilized and sterilized by radiation or ethylene oxide gas, ready for use (Fig. 1A).

\section{Surgical treatment}

Surgical treatments, including extractions, were performed under general anesthesia, for which tiletaminezolazepam (Zoletil 50 ${ }^{\circledR}$, Virbao, Carros, France, 5-10 mg/ $\mathrm{kg}$ ) and Xylazine-HCl (Rompum ${ }^{\circledR}$, Bayer Korea, Seoul, Korea, $0.15 \mathrm{ml} / \mathrm{kg}$ ) were mixed and administered by intra- muscular injection. Teeth were extracted one month before the experiment, to manufacture the autogenous tooth bone graft material. To create the bone defects and apply the membranes, local anesthesia was performed on mandibular third and fourth premolars using $2 \%$ lidocaine $\mathrm{HCl}$; buccal sulcular and vertical incisions were made followed by buccal bone plates of the roots, exposed by lifting fullthickness flaps in the buccal direction. After identification of the position of mesial and distal roots in the mandibular third and fourth premolars, critical bone defects, measuring $5 \mathrm{~mm}$ from the ceiling of the furcation to the root apex, $4 \mathrm{~mm}$ in the mesio-distal direction, and $3 \mathrm{~mm}$ in the buccolingual direction $(5 \times 4 \times 3 \mathrm{~mm})$, were created between the mesial and distal roots, using a carbide round bur (Fig. 1B). To remove all cementum on the root surface, full root
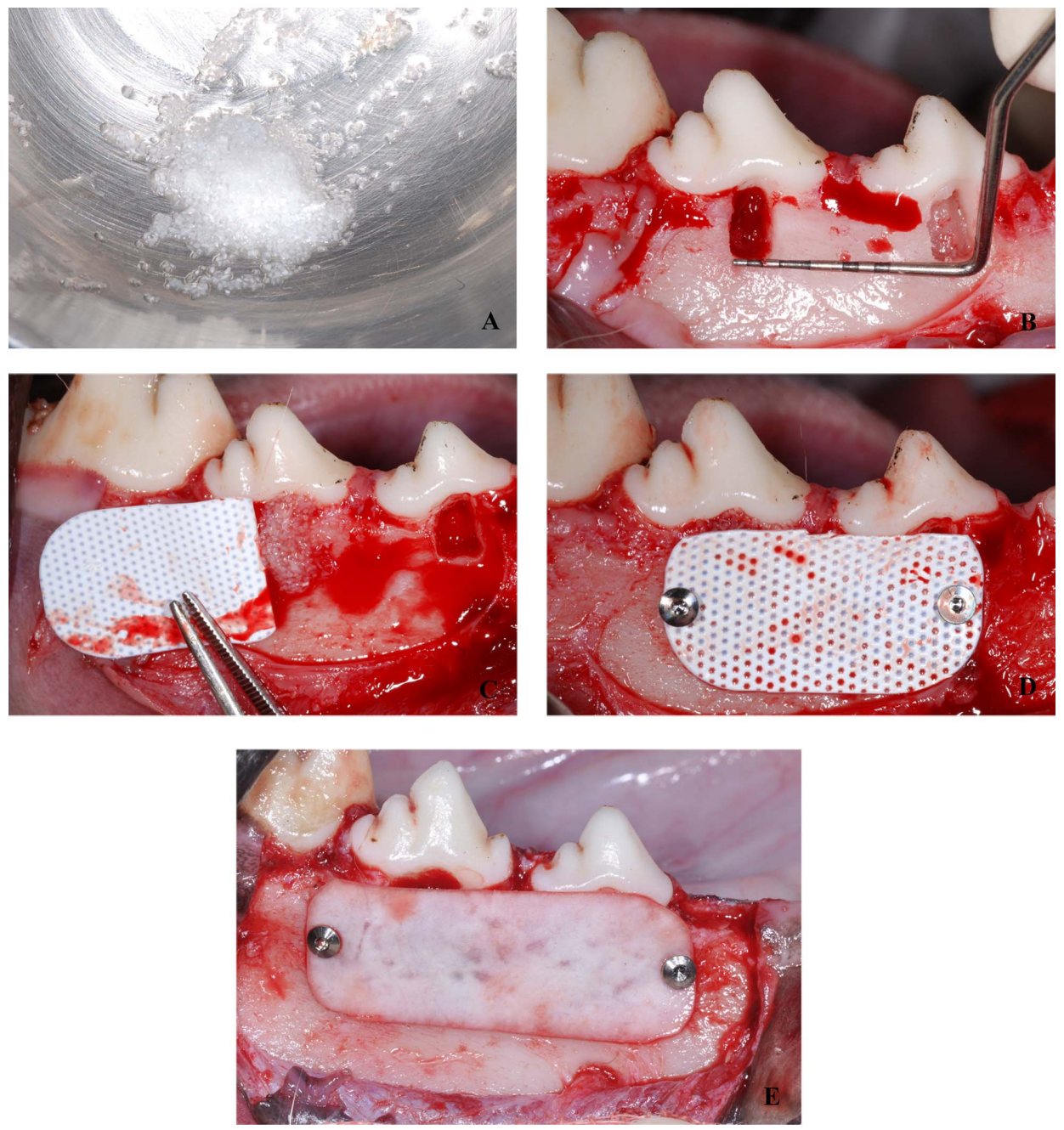

Fig. 1. Clinical procedure. (A) Autogenous tooth bone graft was prepared for bone grafting procedure. (B) Critical class II furcation defects $\left(5 \times 4 \times 3 \mathrm{~mm}^{3}\right)$ were formed at lower third and fourth premolar, respectively. (C) Autogenous tooth bone graft was placed at experimental group defects. Control group defects were remained empty. (D) PTFE non-resorbable membrane and Bone Tack ${ }^{\circledR}$ were placed on the defects. (E) Resorbable collagen membrane and Bone Tack ${ }^{\circledR}$ were placed on the defects. 
planning was performed using a dental rotator and curette; a large amount of water was used for washing and to prevent damage by excessive heat generated during the removal of alveolar bone and roots. For the control group, only non-resorbable PTFE membranes were used without implantation of ATBG to bone defects (Fig. 1C). For the experimental groups, the implantation of ATBG was carried out to bone defects, followed by either non-resorbable PTFE (Fig. 1D) or resorbable collagenous (Fig. 1E) membranes in experimental groups 1 and 2, respectively. Membranes were trimmed to cover more than $3 \mathrm{~mm}$ from the margin of bone defects, and fixed with Bone tack ${ }^{\circledR}$ (ACE Surgical Supply Co., Brockton, USA); flaps were then closed with absorbable sutures (Surgifit ${ }^{\circledR}$, AILEE Company Limited, Busan, Korea). For post-operative care, antibiotics (Gentamicin sulfate, Daesung, Gwangju, Korea, 0.1 $\mathrm{ml} / \mathrm{kg}$ ) were administered by intramuscular injection once daily for 5 days, and mouths were washed with $0.12 \%$ chlorhexidine (Daewoong Phar, Seoul, Korea) twice daily for 2 weeks. We had 8 weeks follow-up period. First, we performed the experiment in 8-week groups and then in 4week groups after 4 weeks. Ten teeth from each group were assessed and were divided into two groups ( 5 teeth per group) that had either 4 or 8 weeks of healing time, respectively. Ten experimental animals were sacrificed using an excessive dose of tiletamine-zolazepam on the same day, from which tissues, including roots, were collected.

\section{Histological evaluation}

Collected tissue fragments were fixed in $10 \%$ buffered formalin for one week, followed by full decalcification with $10 \%$ formic acid for more than two weeks. Paraffin blocks of tissue sections were manufactured by a conventional method; $7 \mu \mathrm{m}$ thick sections were made in the mesio-distal direction using a rotary microtome, followed by staining with hematoxylin-eosin (H-E) and light microscopy.

Histological evaluation included analyses of: root resorption, ankyloses of roots and alveolar bone, formation of new cementum, new bone formation, restoration of periodontal ligaments, and degrees of epithelial migration and tissue inflammation.

\section{Histomorphometric evaluation}

For histomorphometric evaluation, a digital camera (LEICA ICC50, Wetzlar, Hesse, Germany) connected to a light microscope (LEICA DM750, Wetzlar, Hesse, Germany)

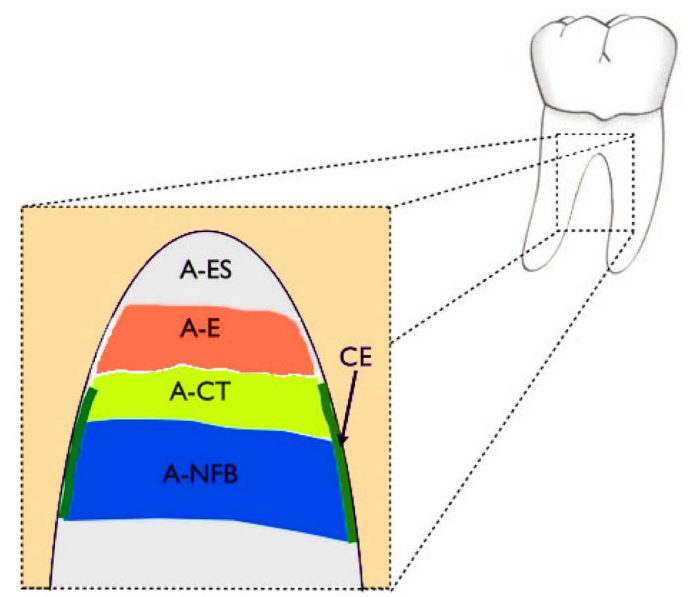

Fig. 2. Schematic illustration representing the histomorphometric measurements performed in the furcation area. Area measurements are as follows: A-NFB, A-CT, A-E and A-ES. Linear measurement is as follows: CE. A-NFB: area of newly formed bone, A-CT: area of connective tissue, A-E: area of epithelium, A-ES: area of empty space, CE: cementum extension.

was used to obtain images of tissues. All measurements were taken by the same investigator, who had no information about the procedure, using the iMT program. Each tissue was measured three times, and the mean of these measurements was calculated.

Measured items included (Fig. 2):
A. Area of newly formed bone (A-NFB)
B. Area of connective tissue (A-CT)
C. Area of epithelium (A-E)
D. Area of empty space (A-ES)
E. Cementum extension (CE)

A-NFB, A-CT, A-E, and A-ES were calculated as rates $(\%)$ of each item in the total area of bone defects. For CE, the length of the root surface in the total area of bone defects was linearly measured and, with newly formed cementum, was calculated as a rate $(\%)$.

\section{Statistical analysis}

A general statistical program, SPSS (SPSS 12.0, SPSS Inc., Chicago, IL, USA), was used for the analyses. Each item was measured from each tissue section, and mean values were calculated and used for analysis. Measurement items were calculated as rates (\%). The betweengroup experimental values were examined by Kruskal Wallis non-parametric tests; experimental values depending on healing period were compared by Mann-Whitney non-parametric tests. Probability values $(\mathrm{P})<0.05$ were accepted as statistically significant. 


\section{Results}

\section{Clinical observations}

All dogs, except one (exposure of non-resorbable membrane), underwent a healing procedure for 4-8 weeks. All groups showed similar clinical findings accompanied by small inflammatory responses. No gingival recessions were observed, except in one dog in which the membrane was exposed.

\section{Histological analysis}

Four weeks after treatment, in the control group, most bone defects were filled with granulomatous connective tissue containing micro-vessels. Partial bony restoration was observed and it was immature newly-formed bone tissue grown from the base during formation of network structures. Despite the absence of abnormal inflammatory findings, resorption was observed on some tooth surfaces. Partial cementum were also evident along the tooth surfaces (Fig. 3). In experimental group-1, multiple ATBGs in bone defect were observed, surrounded by fibrillar connective tissue with no inflammatory findings, fused with adjacent ATBGs surrounded by thin osteoid or immature bone tissue. Some ATBGs, that had grown from lower bone tissues, were found embedded in mature bone tissues, and showed desirable direct bony fusion with newly formed bone tissues. In addition, partial regeneration of cementum and periodontal ligament like tissues were observed along the root surface (Fig. 3). In experimental group-2, ATBGs in regions adjacent to existing bones were embedded in newly formed bone tissue, unified without distinct inflammatory responses. A number of ATBGs were found scattered in fibrillar connective tissues, without fusion to newly formed bone tissues but rather to a few adjacent ATBGs, surrounded by thin oste-
A
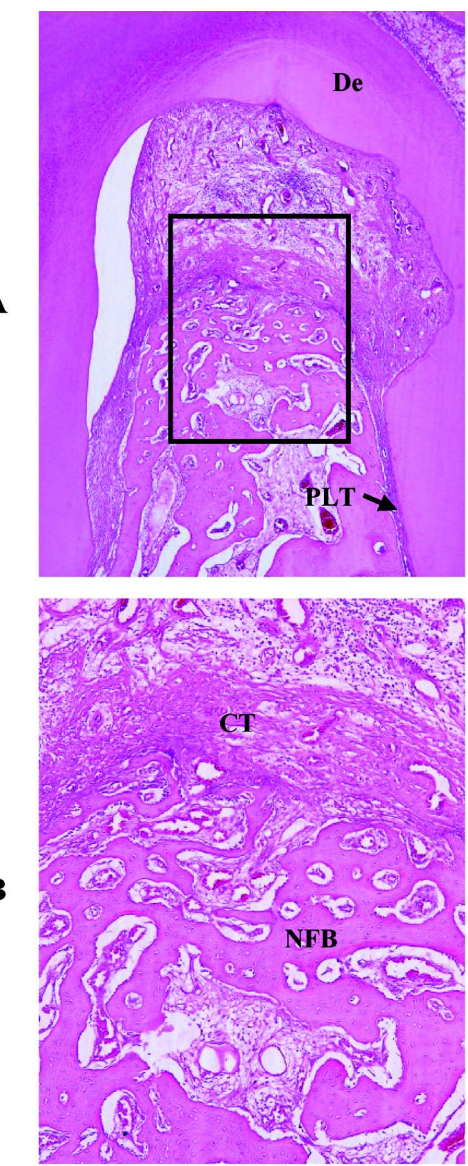

Control (e-PTFE only)
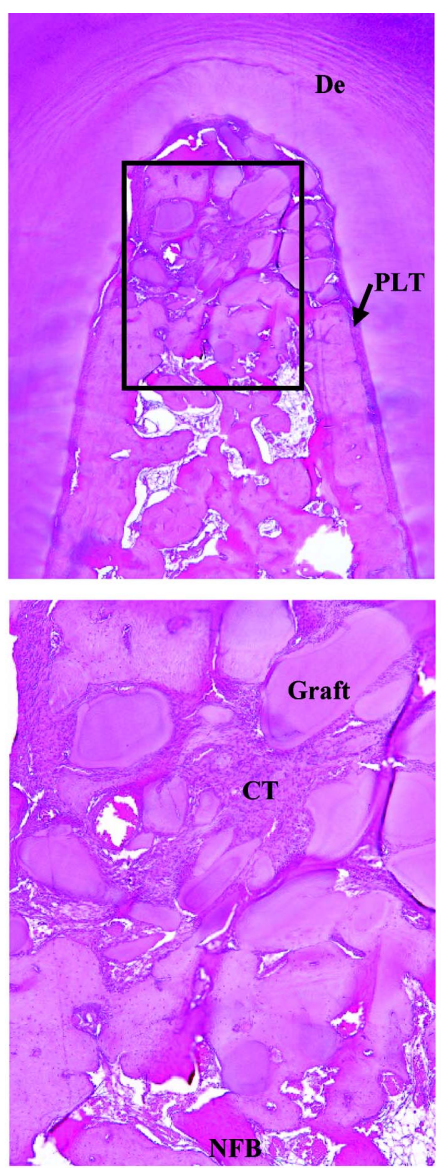

e-PTFE + ATBG
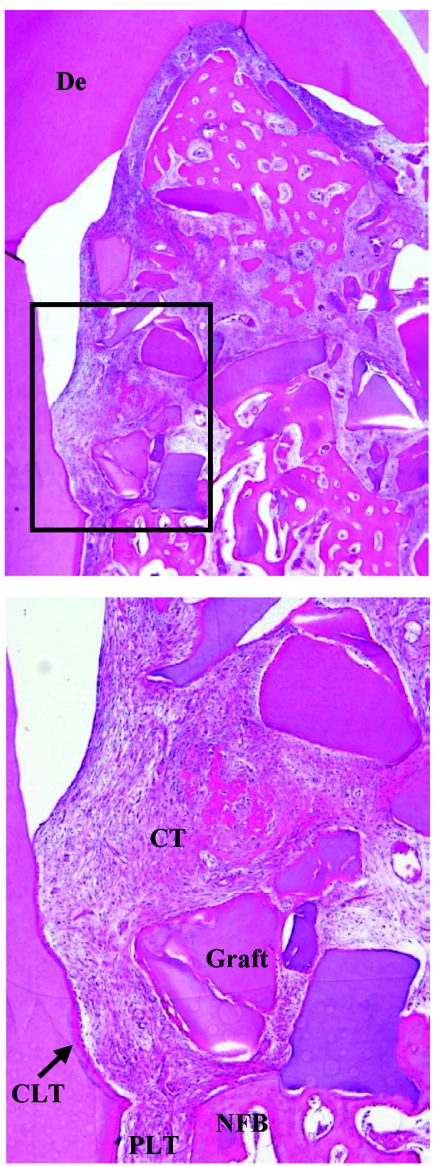

$\mathrm{RCM}+\mathrm{ATBG}$

Fig. 3. Histological view of the mesio-distally sectioned furcation area at 4 weeks after treatment (H-E stain). Original magnifications (A) x40 and (B) x100. De: dentin, CT: connective tissue, NFB: newly formed bone, CLT: cementum like tissue, PLT: periodontal ligament like tissue, PTFE: Polytetrafluoroethylene non-resorbable membrane, ATBG: autogenous tooth bone graft, RCM: resorbable collagen membrane. 
oid or immature bone tissues. Cementum like tissue were formed along the root surface, and partial restoration of periodontal ligament like tissue were observed (Fig. 3).

Eight weeks after treatment, in the control group, most bone defects were filled with dense fibrillar connective tissues containing micro-vessels, and partial bony restoration by semi-mature bone from base parts was observed. There were no abnormal inflammatory findings, and cementum like tissue were partially observed along the tooth surface, while restorations of normal periodontal ligament like tissue were weak (Fig. 4). In experimental group-1, new bone tissues were well formed, resulting in complete restoration of mature bone containing adipose mesenchymal tissue. Embedded ATBGs were directly fused within newly formed bony spurs. The cementum and periodontal ligament like tissues were also well restored to normal structures along the root surfaces of bone defects (Fig. 4). In experimental group-2, new bone tissues were actively formed, surrounding ATBGs at bone defects, achieving desirable bony restoration; some bone tissues showed mature bone patterns with lamellar structures. Multiple ATBGs were embedded and unified with newly formed bone tissue, whereas some ATBGs, surrounded by fibrillar connective tissues, showed weak osteoid deposition. Thickness of cementum like tissue and periodontal ligament like tissue were relatively well restored along the root surface of bone defects (Fig. 4).

\section{Histomorphometric analysis}

Four weeks after treatment, in the control, experimental1, and experimental-2 groups: A-NFBs were $42.4 \% \pm 34.1 \%$, $66.6 \% \pm 19.1 \%$, and $53.7 \% \pm 6.7 \%$, respectively; A-CTs were $46.9 \% \pm 23.9 \%, 26.3 \% \pm 11.9 \%$, and $38.0 \% \pm 8.1 \%$, respectively; A-Es were $2.9 \% \pm 6.4 \%, 0 \%$, and $0 \%$, respectively; CEs were $45.5 \% \pm 36.4 \%, 74.6 \% \pm 21.0 \%$, and $72.5 \% \pm 23.3 \%$, respectively (Table 1 ). In the control,
A
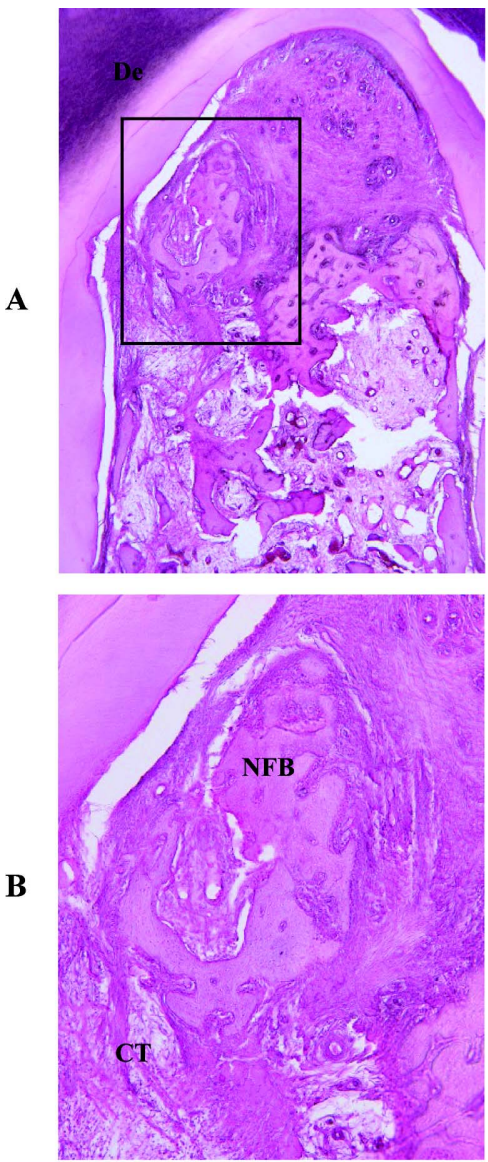

Control (e-PTFE only)
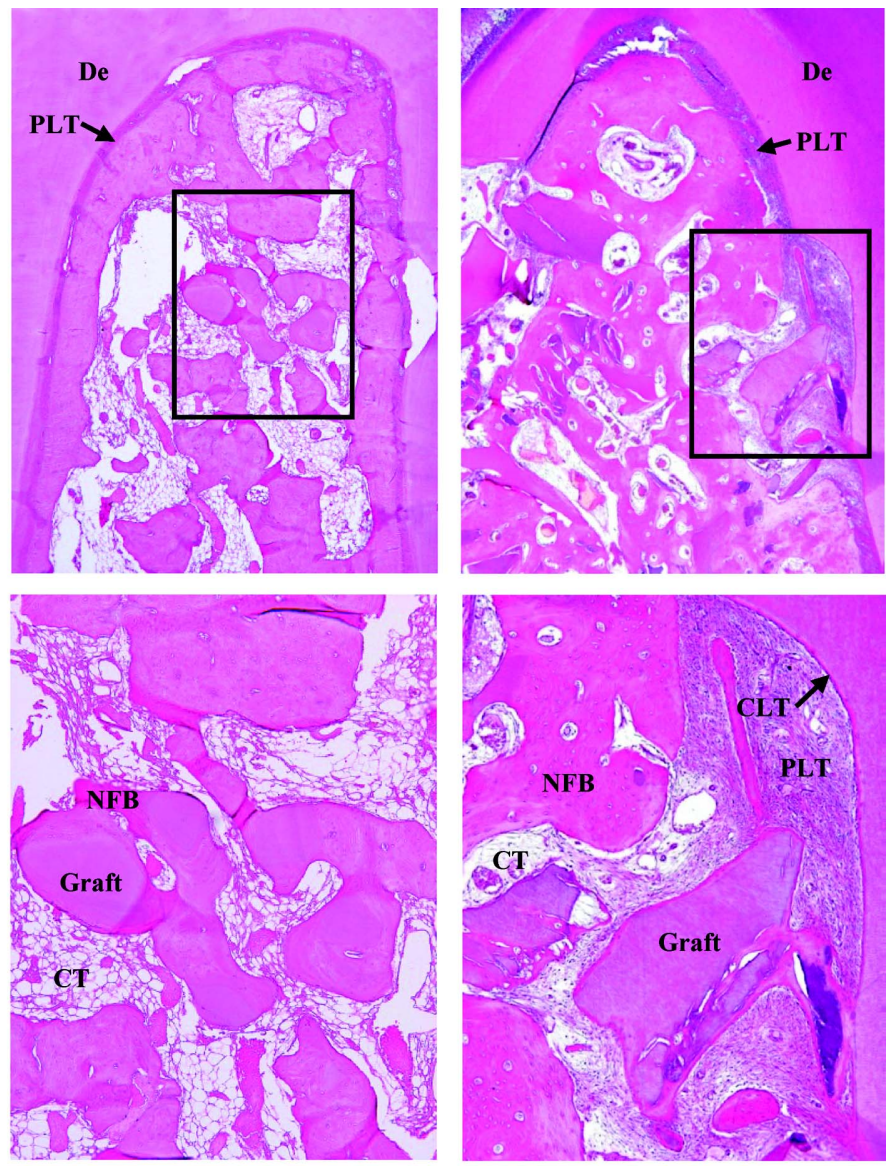

e-PTFE + ATBG

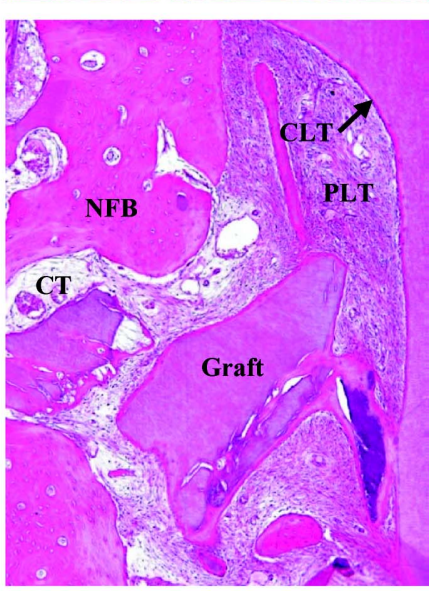

$\mathrm{RCM}+\mathrm{ATBG}$

Fig. 4. Histological view of the mesio-distally sectioned furcation area at 8 weeks after treatment (H-E stain). Original magnifications (A) $x 40$ and (B) x100. De: dentin, CT: connective tissue, NFB: newly formed bone, CLT: cementum like tissue, PLT: periodontal ligament like tissue, PTFE: Polytetrafluoroethylene non-resorbable membrane, ATBG: autogenous tooth bone graft, RCM: resorbable collagen membrane. 
Table 1. Percentage of parameters

\begin{tabular}{cllllcc}
\hline & Group & n & A-NFB (\%) & A-CT (\%) & A-E (\%) & CE (\%) \\
\hline \multirow{4}{*}{4 weeks } & e-PTFE (control) & 5 & $42.4 \pm 34.1$ & $46.9 \pm 23.9$ & $2.9 \pm 6.4$ & $45.5 \pm 36.4$ \\
& e-PTFE + ATBG & 5 & $66.6 \pm 19.1$ & $26.3 \pm 11.9$ & 0 & $74.6 \pm 21.0$ \\
& RCM + ATBG & 5 & $53.7 \pm 6.7$ & $38.0 \pm 8.1$ & 0 & $72.5 \pm 23.3$ \\
\multirow{5}{*}{ 8 weeks } & e-PTFE (control) & 5 & $47.3 \pm 33.7$ & $48.8 \pm 32.6$ & $0.6 \pm 0.8$ & $60.2 \pm 41.8$ \\
& e-PTFE + ATBG & 5 & $61.5 \pm 33.2$ & $34.8 \pm 34.0$ & 0 & $73.2 \pm 36.8$ \\
& RCM + ATBG & 5 & $71.5 \pm 22.9$ & $22.8 \pm 16.2$ & 0 & $63.3 \pm 32.8$ \\
\hline
\end{tabular}

Mean \pm standard deviation; $\mathrm{n}=$ number of specimens. Kruskal Wallis test was used for the analysis of parameters between the groups. There was no statistically significant difference $(p<0.05)$ between the groups. Mann-Whitney test was used for the analysis of parameters between 4 weeks and 8 weeks. There was no statistically significant difference $(p<0.05)$ between 4 weeks and 8 weeks. A-NFB: area of newly formed bone, A-CT: area of connective tissue, A-E: area of epithelium, A-ES: area of empty space, CE: cementum extension, ePTFE: expended-polytetrafluoroethylene non-resorbable membrane, ATBG: autogenous tooth bone graft, RCM: resorbable collagen membrane.

experimental-1, and experimental-2 groups, newly formed tissue areas were $92.2 \% \pm 13.0 \%, 97.4 \% \pm 4.4 \%, 98.1 \% \pm$ $2.8 \%$, respectively, and Empty space areas were $7.8 \% \pm 13.0 \%$, $2.6 \% \pm 4.4 \%$, and $1.9 \% \pm 2.8 \%$, respectively (Table 2 ). While there were no statistically significant differences in any measurement between the control and experimental groups 4 weeks after treatment $(\mathrm{P}>0.05)$, the amounts of A-NFB and newly formed tissue area in the experimental groups tended to be higher than in the control group.

Eight weeks after treatment, in the control, experimental-1, and experimental-2 groups: A-NFBs were 47.3\% \pm $33.7 \%, 61.5 \% \pm 33.2 \%$, and $71.5 \% \pm 22.9 \%$, respectively; A-CTs were $48.8 \% \pm 32.6 \%, 34.8 \% \pm 34.0 \%$, and $22.8 \%$ $\pm 16.2 \%$, respectively; A-Es were $0.6 \% \pm 0.8 \%, 0 \%$, and $0 \%$, respectively; CEs were $60.2 \% \pm 41.8 \%, 73.2 \% \pm 36.8 \%$, and $63.3 \% \pm 32.8 \%$, respectively (Table 1 ). In the control,

Table 2. Percentage of furcation filling

\begin{tabular}{clccc}
\hline \multirow{5}{*}{ 4 Group } & n weeks & \multicolumn{2}{c}{ Newly formed } \\
tissue area (\%) & Empty space & area (\%) \\
& e-PTFE (control) & 5 & $92.2 \pm 13.0$ & $7.8 \pm 13.0$ \\
& e-PTFE + ATBG & 5 & $97.4 \pm 4.4$ & $2.6 \pm 4.4$ \\
& RCM + ATBG & 5 & $98.1 \pm 2.8$ & $1.9 \pm 2.8$ \\
& e-PTFE (control) & 5 & $96.7 \pm 3.7$ & $3.3 \pm 3.7$ \\
8 weeks & e-PTFE + ATBG & 5 & $96.8 \pm 5.7$ & $3.2 \pm 5.7$ \\
& RCM + ATBG & 5 & $99.6 \pm 0.8$ & $0.4 \pm 0.8$ \\
\hline
\end{tabular}

Mean \pm standard deviation; $\mathrm{n}=$ number of specimens. Kruskal Wallis test was used for the analysis of parameters between the groups. There was no statistically significant difference $(p<0.05)$ between the groups. Mann-Whitney test was used for the analysis of parameters between 4 weeks and 8 weeks. There was no statistically significant difference $(p<0.05)$ between 4 weeks and 8 weeks. ePTFE: expended-polytetrafluoroethylene non-resorbable membrane, ATBG: autogenous tooth bone graft, RCM: resorbable collagen membrane. experimental-1, and experimental-2 groups, newly formed tissue areas were $96.7 \% \pm 3.7 \%, 96.8 \% \pm 5.7 \%$, and $99.6 \%$ $\pm 0.8 \%$, respectively, and Empty space areas were 3.3\% \pm $3.7 \%, 3.2 \% \pm 5.7 \%$, and $0.4 \% \pm 0.8 \%$, respectively (Table 2). While there were no statistically significant differences in any measurement between the control and experimental groups 8 weeks after treatment $(\mathrm{P}>0.05)$, the amounts of A-NFB and newly formed tissues in the experimental groups tended to be higher than in the control group.

\section{Discussion}

The theory of regenerative periodontal therapy is based on the new attachment concept. In guided tissue regeneration, a membrane is placed between bone defects and upper gingiva to artificially block epithelial downgrowth and proliferation of gingival connective tissues, by which proliferation of undifferentiated cells in the periodontal ligament is induced, promoting complete regeneration of periodontal tissue comprised of newly formed cementum, alveolar bone, and periodontal ligaments [24,25].

Although Class II furcation defects, commonly found as periodontal lesions, can be an indication for regenerative periodontal therapy via methods such as guided tissue regeneration, treatment is complicated and challenging due to device accessibility. In a systematic review of papers from periodontics related journals until 2002, Murphy and Gunsolley [26] reported that guided tissue regeneration for the treatment of intrabony pockets and furcation lesions was more effective than flap in achieving a clinical attachment and reducing the pocket depth when probing. In a systematic review of regenerative periodontal therapy 
in 2008, Sculean et al. [27] reported that the use of barrier membranes with grafting materials is effective in regenerating periodontal tissue, particularly in bone repair. However, they reported that no additional benefit was obseved in the treatment of Class II furcation defects.

With the regenerative periodontal therapy, using surgically formed Class II furcation defects, the present study evaluated the degree of periodontal tissue regeneration histologically and histomorphometrically, depending on the presence or absence of ATBG and membrane type. Novaes et al. [28] were unable to obtain voluntary bone regeneration from the bone defects $(5 \mathrm{~mm}$ high $\times 2 \mathrm{~mm}$ deep) used in their study. Thus, the present study created critical bone furcation defects, measuring $5 \mathrm{~mm}$ from the root apex, $4 \mathrm{~mm}$ mesio-distally, and $3 \mathrm{~mm}$ buccilingually $(5 \times 4 \times 3 \mathrm{~mm})$. Immediately after introducing the defects, full root planning was performed using a dental rotator and curette to remove all cementum from the root surface. It was previously reported that removal of cementum through conventional root planning led to similar bone defects caused by periodontal disease [29,30]. An 8-week healing period was selected based on the report that canine intrabony defect cementumogensis is completed within 8 weeks [31].

Various studies have been performed for the removal of the non-resorbable membranes [32-36], and preceding reports recommend removing the expanded polytetrafluoroethylene (ePTFE) membrane within 4-6 weeks [37-39]. Moreover, previous reports suggest that membrane maintenance for 6 weeks or longer has no additional benefit [40]. In the present study, the membrane was retained until 8 weeks, when the experiment was completed.

Newly formed bone at 8 -weeks amounted to $47.3 \% \pm$ $33.7 \%$ in the control group (with non-resorbable membrane only), $61.5 \% \pm 33.2 \%$ in experimental group-1 (with non-resorbable membrane and bone graft material), and $71.5 \% \pm 22.9 \%$ in experimental group-2 (with resorbable membrane and bone graft material) (Table 1). In other studies, with similar methodologies, Deliberador et al. [41] reported newly formed bone at 3 months amounting to $59.85 \%$, after using autogenous bone and calcium sulfate barriers for the regeneration of Class II furcation defects. Moreover, Macedo et al. [42] reported newly formed bone at 3 months amounting to an average of $70.49 \%$ after using ePTFE membranes only for Class II furcation defects.

Various bone graft materials have been used for the regeneration of Class II furcation defects [10]. Of the clinically applied materials, including autogenous bone, allogenic bone, heterogenous bone, and synthetic bone, autogenous bone is ideal for regenerative periodontal therapy. However, it has potential disadvantages, including limitations in the collectible amount, complications associated with the donor, and issues with resorption after graft. Nevertheless, allogenic and heterogenous bone are associated with the spread of infection and are high in cost; synthetic bone is relatively cheaper and has no risk of infection, but it is has no osteogenesis or osteoinduction capabilities, limiting the formation of viable bone tissue. To overcome these limitations, autogenous bone and other bone graft materials are typically mixed in clinical practice. Hassan et al. [43] reported that autogenous bone is highly superior to synthetic bone when tested by guided bone regeneration.

Chemical composition of the autogenous tooth bone graft material used in this study is highly similar to that of alveolar bone. Alveolar bone is composed of $65 \%$ minerals and $35 \%$ organic materials, while the ATBG is composed of $55 \%$ minerals and $45 \%$ organic materials. The mineral components of ATBG is mostly composed of four types of calcium phosphate: hydroxyapatite (HA), tricalcium phosphate (TCP), octacalcium phosphate (OCP), and amorphous calcium phosphate (ACP). Meanwhile, the organic components contain type 1 collagen and non-collagenous proteins. thus, ATBG displays excellent healing effects though osteoinduction and osteoconduction functions $[18,23,41]$. As such, ATBG is a new graft material that doesn't only have bone regeneration capabilities similar to autogenous bone, but also can overcome the limitations of allogenic bone, heterogenous bone, and synthetic bone.

This study applied both ATBG and membranes to Class II furcation defects. Histomorphometric evaluation found increased formation of new bone and cementumogensis, compared only non-resorbable membrane use; however, these differences were not statistically significant. Clinical trials [3,44-46] and animal experiments $[47,48]$ on regenerative periodontal therapy using bone graft materials reported contradictory results in the treatment of Class II furcation defects. In a histological study, Caffesse et al. [47] reported that bone graft material added to membranes failed to promote tissue regeneration, whereas other researchers reported that combined use with bone graft material resulted in greater bone filling for furcation defects [48]. In a meta-analysis, Jepsen et al. [49] reported that Class II 
furcation defects should be the main indicator for the guided tissue regeneration technique combined with membranes, and that ePTFE membrane alone can prevent epithelial downgrowth, separate gingival connective tissues and protect clots, leading to clinically satisfactory outcomes.

White et al. [50] examined regenerated bone after treatment of furcation defects using ePTFE membranes by fluorescent microscopy via fluorochrome labels and microradiograph; they found that there was a statistically significant increase in bone regeneration with (compared to without) the use of ePTFE membranes, but there was no statistically significant difference in light microscopy. As a result, they concluded that light microscopy alone was unable to effectively evaluate overall bone response, with a tendency toward underestimation [50]. The present study also attempted histomorphological evaluation by investigation of newly formed tissues, including new bone via light microscopy; we found no statistically significant differences between the control and experimental groups. Thus, various methods, such as fluorescent microscopy and microradiography, should be considered for further analyses of newly formed tissues.

For bone regeneration depending on the type of membrane, the present study found no significant differences. Non-resorbable membranes are disadvantageous, due to a high chance of early membrane exposure and requirement for secondary surgery to remove the membrane. It was reported that bacterial infection by early membrane exposure could lead to failure of the regenerative periodontal therapy; the amount of regenerating tissues decreased after exposure [51,52]. In the present study, exposure of the membrane was observed at only one area in control group, between the fourth and the eighth week. Although the membrane was retained (not removed) until the end of the experiment, there seemed to be no difference in the amount of bone regeneration depending on the type of membrane. Murphy and Gunsolley [26] reported that there was no distinct difference between resorbable and nonresorbable membranes. Moreover, Behfarnia et al. [53] applied three types of resorbable membranes (Biogide ${ }^{\circledR}$, Biomend $^{\circledR}$, and Cytoplast ${ }^{\circledR}$ ) for dehiscence defects, resulting in similar outcomes, and more favorable results than that obtained without membrane application.

To date, there have been various reports on the regenerative periodontal therapy combined with bone graft material and membranes for the treatment of Class II furcation defects. The present study evaluated regenerative periodontal therapy with membranes with/without ATBG, and with graft material combined with different types of membranes. No statistically significant differences were found. These results suggest that ATBG is a stable graft material for use with membranes for the treatment of Class II furcation defects; however, the resorbable feature of membranes has no significant effect on regeneration outcomes.

\section{Acknowledgements}

This study was supported by the Regional Innovation Center for Dental Science \& Engineering, Chosun University, Gwangju, Korea (B0008940).

\section{Conflict of Interest}

The authors declare that they have no competing interests.

\section{ORCID}

$\begin{array}{ll}\text { Keon-Il Yang } & 0000-0001-8789-7743 \\ \text { Ah-Young Cho } & 0000-0002-8926-9430 \\ \text { Jin-Young Yang } & 0000-0003-4913-7692 \\ \text { Hong-In Shin } & 0000-0001-7758-5826 \\ \text { Won-Pyo Lee } & 0000-0003-1911-3454 \\ \text { Byung-Ock Kim } & 0000-0001-8952-617 \mathrm{X} \\ \text { Sang-Joun Yu } & 0000-0001-8818-549 \mathrm{X}\end{array}$

\section{References}

1. Melcher AH. On the repair potential of periodontal tissues. J Periodontol 1976;47:256-260. doi: 10.1902/jop. 1976.47.5.256.

2. Gottlow J, Nyman S, Lindhe J, Karring T, Wennström J. New attachment formation in the human periodontium by guided tissue regeneration. Case reports. J Clin Periodontol 1986;13:604-616. doi: 10.1111/j.1600-051X.1986. tb00854.x.

3. Schallhorn RG, McClain PK. Combined osseous composite grafting, root conditioning, and guided tissue regeneration. Int J Periodontics Restorative Dent 1988; 8:8-31.

4. Walters SP, Greenwell H, Hill M, Drisko C, Pickman K, 
Scheetz JP. Comparison of porous and non-porous teflon membranes plus a xenograft in the treatment of vertical osseous defects: a clinical reentry study. J Periodontol 2003;74:1161-1168. doi: 10.1902/jop.2003.74.8.1161.

5. Pontoriero R, Lindhe J, Nyman S, Karring T, Rosenberg E, Sanavi F. Guided tissue regeneration in degree II furcation-involved mandibular molars. A clinical study. J Clin Periodontol 1988;15:247-254. doi: 10.1111/j.1600051X.1988.tb01578.x.

6. Pontoriero R, Lindhe J, Nyman S, Karring T, Rosenberg E, Sanavi F. Guided tissue regeneration in the treatment of furcation defects in mandibular molars. A clinical study of degree III involvements. J Clin Periodontol 1989;16:170-174. doi: 10.1111/j.1600-051X.1989.tb01635.x.

7. Pihlstrom BL, McHugh RB, Oliphant TH, Ortiz-Campos C. Comparison of surgical and nonsurgical treatment of periodontal disease. A review of current studies and additional results after $61 / 2$ years. J Clin Periodontol 1983;10:524-541. doi: 10.1111/j.1600-051X.1983.tb02182.x.

8. Tonetti MS, Pini-Prato G, Cortellini P. Periodontal regeneration of human intrabony defects. IV. Determinants of healing response. J Periodontol 1993;64:934-940. doi: 10.1902/jop.1993.64.10.934.

9. Machtei EE, Schallhorn RG. Successful regeneration of mandibular Class II furation defects: An evidence-based treatment approach. Int J Periodontics Restorative Dent 1995;15:146-167.

10. Nasr HF, Aichelmann-Reidy ME, Yukna RA. Bone and bone substitutes. Periodontol 2000 1999;19:74-86. doi: 10.1111/j.1600-0757.1999.tb00148.x.

11. Lang NP, Lindhe J. Concepts of periodontal tissue regeneration. In: Karring T, Lindhe J, editors. Clinical periodontology and implant dentistry. $6^{\text {th }}$ ed. Chichester: John Wiley \& Sons, Ltd; 2015. p. 536-555.

12. Schallhorn RG. Long term evaluation of osseous grafts in periodontal therapy. Int Dent J 1980;30:101-116.

13. Kim SG, Yeo HH, Kim YK. Grafting of large defects of the jaws with a particulate dentin-plaster of Paris combination. Oral Surg Oral Med Oral Pathol Oral Radiol Endod 1999;88:22-25. doi: 10.1016/S1079-2104(99)70188-5.

14. Yeomans JD, Urist MR. Bone induction by decalcified dentine implanted into oral, osseous and muscle tissues. Arch Oral Biol 1967;12:999-1008. doi: 10.1016/00039969(67)90095-7.

15. Bessho K, Tnaka N, Maysumoto J, Tagawa T, Murata M. Human dentin-matrix-derived bone morphogenetic protein. J Dent Res 1991;70:171-175. doi: 10.1177/ 00220345910700030301.

16. Kim YK, Yeo HH, Ryu CH, Lee HB, Beon UR, Cho JO. An experimental study on the tissue reaction of toothash implanted in mandible body of the mature dog. Maxillofac Plast Reconstr Surg 1993;15:129-136.

17. Kim YK, Yeo HH, Yang IS, Seo JH, Cho JO. Implanta- tion of toothash combined with plaster of Paris: experimental study. Maxillofac Plast Reconstr Surg 1994;16:122129.

18. Kim YK. The experimental study of the implantation of toothash and plaster of Paris and guided tissue regeneration using Lyodura. J Korean Assoc Oral Maxillofac Surg 1996;22:297-306.

19. Kim YK, Yeo HH. Transmitted electronic microscopic study about the tissue reaction after the implantation of toothash. J Korean Assoc Oral Maxillofac Surg 1997;23: 283-289.

20. Kim YK, Kim SG, Lee JG, Lee MH, Cho JO. An experimental study on the healing process after the implantation of various bone substitutes in the rats. J Korean Assoc Oral Maxillofac Surg 2001;27:15-24.

21. Kim YK, Kim SG, Lee JH. Cytotoxicity and hypersensitivity test of toothash. Maxillofac Plast Reconstr Surg 2001;23:391-395.

22. Kim YK, Kim SG, Byeon JH, Lee HJ, Um IU, Lim SC, Kim SY. Development of a novel bone grafting material using autogenous teeth. Oral Surg Oral Med Oral Pathol Oral Radiol Endod 2010;109:496-503. doi: 10.1016/ j.tripleo.2009.10.017.

23. Kim YK, Kim SG, Yun PY, Yeo IS, Jin SC, Oh JS, Kim HJ, Yu SK, Lee SY, Kim JS, Um IW, Jeong MA, Kim GW. Autogenous teeth used for bone grafting: a comparison with traditional grafting materials. Oral Surg Oral Med Oral Pathol Oral Radiology 2014;117:39-45. doi: 10.1016/j.oooo.2012.04.018.

24. Melcher AH. On the repair potential of periodontal tissues. J Periodontol 1976;47:256-260. doi: 10.1902/jop. 1976.47.5.256.

25. Bosshardt DD, Sculean A. Does periodontal tissue regeneration really work? Periodontol 2000. 2009;51:208-219. doi: 10.1111/j.1600-0757.2009.00317.x.

26. Murphy KG, Gunsolley JC. Guided tissue regeneration for the treatment of periodontal intrabony and furcation defects. Ann Periodontol 2003;8:266-302. doi: 10.1902/ annals.2003.8.1.266.

27. Sculean A, Nikolidakis D, Schwarz F. Regeneration of periodontal tissues: combinations of barrier membranes and grafting materials-biological foundation and preclinical evidence: a systematic review. J Clin Periodontol 2008;35:106-116. doi: 10.1111/j.1600-051X.2008.01263.x.

28. Novaes AB Jr, Tamani JP, Oliveira PT, Palioto DB, Almeida AL. Root trunk concavities as a risk factor for regenerative procedures of Class II furcation lesions in dogs. J Periodontol 2001;72:612-619. doi: 10.1902/ jop.2001.72.5.612.

29. Jones WA, O'Leary TJ. The effectiveness of in vivo root planning in removing bacterial endotoxin from the roots of periodontally involved teeth. J Periodontol 1978;49: 337-342. 
30. Wikesjo UM, Selvig KA, Zimmerman G, Nilveus R. Periodontal repair in dogs: healing in experimentally created chronic periodontal defects. J Periodontol 1991; 62:258-263. doi: 10.1902/jop.1991.62.4.258.

31. Choi SH, Kim CK, Cho KS, Huh JS, Sorensen RG, Wozney JM, Wikesjö UM. Effect of recombinant human bone morphogenetic protein-2/absorbable collagen sponge (rhBMP-2/ACS) on healing in 3-wall intrabony defects in dogs. J Periodontol 2002;73:63-72. doi: 10.1902/ jop.2002.73.1.63.

32. Selvig KA, Kersten BG, Chamberlain AD, Wikesjo UM, Nilveus RE. Regenerative surgery of intrabony periodontal defects using ePTFE barrier membranes: scanning electron microscopic evaluation of retrieved membranes versus clinical healing. J Periodontol 1992;63:974-978. doi: 10.1902/jop.1992.63.12.974.

33. Machtei EE. The effect of membrane exposure on the outcome of regenerative procedures in humans: a metaanalysis. J Periodontol 2001;72:512-516. doi: 10.1902/ jop.2001.72.4.512.

34. Sander L, Frandsen EV, Arnbjerg D, Warrer K, Karring T. Effect of local metronidazole application on periodontal healing following guided tissue regeneration. Clinical findings. J Periodontol 1994;65:914-920. doi: 10.1902/ jop.1994.65.10.914.

35. Novaes AB, Jr., Gutierrez FG, Francischetto IF, Novaes AB. Bacterial colonization of the external and internal sulci and of cellulose membranes at time of retrieval. J Periodontol 1995;66:864-869. doi: 10.1902/jop.1995.66. 10.864 .

36. Anderegg CR, Metzler DG, Nicoll BK. Gingiva thickness in guided tissue regeneration and associated recession at facial furcation defects. J Periodontol 1995;66:397402. doi: 10.1902/jop.1995.66.5.397.

37. Murphy KG. Postoperative healing complications associated with Gore-Tex periodontal material. Part I. Incidence and characterization. Int J Periodontics Restorative Dent 1995;15:363-375.

38. Murphy KG. Postoperative healing complications associated with Gore-Tex periodontal material. Part II. Effect of complications on regeneration. Int $\mathrm{J}$ Periodontics Restorative Dent 1995;15:548-561.

39. Caton J, Wagener C, Polson A, Nyman S, Franz B, Bouwsma $\mathrm{O}$, Blieden T. Guided tissue regeneration in interproximal defects in the monkey. Int $\mathrm{J}$ Periodontics Restorative Dent 1992;12:266-277.

40. Caffesse RG, Smith BA, Castelli WA, Nasjleti CE. New attachment achieved by guided tissue regeneration in beagle dogs. J Periodontol 1988;59:589-594. doi: 10.1902/ jop.1988.59.9.589.

41. Deliberador TM, Nagata MJ, Furlaneto FA, Melo LG, Okamoto T, Sundefeld ML, Fucini SE. Autogenous bone graft with or without a calcium sulfate barrier in the treatment of Class II furcation defects: a histologic and histometric study in dogs. J Periodontol 2006;77:780789. doi: 10.1902/jop.2006.050209.

42. Macedo GO, Souza SL, Novaes AB, Jr., Grisi MF, Taba M, Jr., Palioto DB. Effect of early membrane removal on regeneration of Class II furcation defects in dogs. J Periodontol 2006;77:46-53. doi: 10.1902/jop.2006.77.1.46.

43. Hassan KS, Kassim A, Ogaly AU. A comparative evaluation of immediate dental implant with autogenous versus synthetic guided bone regeneration. Oral Surg Oral Med oral Pathol Oral Radiol Endod 2008;106:8-15. doi: 10.1016/j.tripleo.2008.07.015.

44. Wallace SC, Gellin RG, Miller MC, Mishkin DJ. Guided tissue regeneration with and without decalcified freezedried bone in mandibular Class II furcation invasions. J Periodontol 1994;65:244-254. doi: 10.1902/jop.1994.65.3. 244.

45. Calongne KB, Aichelmann-Reidy ME, Yukna RA, Mayer ET. Clinical comparison of microporous biocompatible composite of PMMA, PHEMA and calcium hydroxide grafts and expanded polytetrafluoroethylene barrier membranes in human mandibular molar Class II furcations. A case series. J Periodontol 2001;72:1451-1459. doi: 10.1902/jop.2001.72.10.1451.

46. Luepke PG, Mellonig JT, Brunsvold MA. A clinical evaluation of a bioresorbable barrier with and without decalcified freeze-dried bone allograft in the treatment of molar furcations. J Clin Periodontol 1997;24:440-446. doi: 10.1111/j.1600-051X.1997.tb00209.x.

47. Caffesse RG, Nasjleti CE, Plotzke AE, Anderson GB, Morrison EC. Guided tissue regeneration and bone grafts in the treatment of furcation defects. J Periodontol 1993;64:1145-1153. doi: 10.1902/jop.1993.64.11s.1145.

48. Lekovic V, Kenney EB. Guided tissue regeneration using calcium phosphate implants together with 4 different membranes. A study on furcations in dogs. J Periodontol 1993;64:1154-1156. doi: 10.1902/jop.1993.64.11s.1154.

49. Jepsen S, Eberhard J, Herrera D, Needleman I. A systematic review of guided tissue regeneration for periodontal furcation defects. What is the effect of guided tissue regeneration compared with surgical debridement in the treatment of furcation defects? J Clin Periodontol 2002;29:103-116. doi: 10.1034/j.1600-051X.29.s3.6.x.

50. White C, Hancock EB, Garetto LP, Kafrawy AA. A histomorphometric study on the healing of Class III furcations utilizing bone labelling in beagle dogs. J Periodontol 1994;65:84-92. doi: 10.1902/jop.1994.65.1.84.

51. Mombelli A, Lang NP, Nyman S. Isolation of periodontal species after guided tissue regeneration. J Periodontol 1993;64:1171-1175. doi: 10.1902/jop.1993.64.11s.1171.

52. Cortellini P, Pini Prato G, Tonetti MS. Interproximal free gingival grafts after membrane removal in guided tissue regeneration treatment of intrabony defects. A random- 
Keon-Il Yang et al.

ized controlled clinical trial. J Periodontol 1995;66:488493. doi: 10.1902/jop.1995.66.6.488.

53. Behfarnia P, Khorasani MM, Birang R, Abbas FM. Histological and histomorphometric analysis of animal experimental dehiscence defect treated with three bio absorbable GTR collagen membrane. Dent Res J 2012; 9:574-581. 